\title{
APLICAÇÕES DA RIBOTIPAGEM NA EPIDEMIOLOGIA MOLECULAR DE INFECÇÕES BACTERIANAS
}

\author{
RIBOTYPING ON MOLECULAR EPIDEMIOLOGY OF BACTERIAL INFECTIONS
}

Ana Lúcia C. Darini ${ }^{1}$; Vanda D. Magalhães ${ }^{2} \&$ Luciana S. P. Crott $^{1}$

\begin{abstract}
1Docentes do Departamento de Análises Clínicas, Toxicológicas e Bromatológicas da Faculdade de Ciências Farmacêuticas de Ribeirão Preto da Universidade de São Paulo; ${ }^{2}$ Doutora em Microbiologia, Coordenadora do Laboratório de Biologia Molecular do Hospital Israelita Albert Einstein de São Paulo.

CorReSPONDÊnCIA: Av. do Café s/n, CEP: 14040-903 - Ribeirão Preto - SP. Fone: (016) 602-4260 - Fax (016) 633-1092.

E-mail: aldarini@fcfrp.usp.br ou aldarini@usp.br
\end{abstract}

DARINI ALC; MAGALHÃES VD \& CROTT LSP. Aplicações da ribotipagem na epidemiologia molecular de infecções bacterianas. Medicina, Ribeirão Preto, 30: 73-80, jan./mar. 1998.

RESUMO: A tipagem molecular do genoma bacteriano, na maioria das vezes, envolve a análise de fragmentos de restrição do DNA cromossômico. Desde que a ribotipagem foi descrita, em 1986, tem sido amplamente utilizada para analisar relações taxonômicas e/ou epidemiológicas entre os diferentes grupos de organismos. A ribotipagem usa o padrão de restrição do opéron de RNA ribossômico $(r r n)$ como ferramenta epidemiológica e tem fornecido ótimos resultados para a detecção de polimorfismo do comprimento dos fragmentos de restrição (RFLPS). O número de opérons $r r n$ da bactéria está diretamente relacionado ao potencial discriminatório da técnica, fornecendo um maior ou menor número de bandas.

UNITERMOS: Epidemiologia Molecular. Técnicas para Tipagem de Bactérias. Infecções Bacterianas.

\section{1 - MÉTODOS DE TIPAGEM BACTERIANA}

Uma investigação epidemiológica da etiologia de um surto infeccioso baseia-se na construção de um estudo estatístico extremamente cuidadoso e na delimitação do surto pela identificação correta da linhagem bacteriana envolvida.

Métodos baseados em características fenotípicas têm sido comparados desfavoravelmente com aqueles que examinam o cromossomo bacteriano. A biotipagem, por exemplo, usada, principalmente e de forma eficaz, na identificação de gêneros e espécies bacterianas, tem se mostrado de pouca valia, mesmo quando comparada com outras técnicas fenotípicas, na discriminação de linhagens ${ }^{1}$.

O perfil de resistência, codificado muitas vezes por plasmídeos, elementos instáveis por definição, é freqüentemente idêntico para linhagens diferentes ${ }^{2}$. A análise do conteúdo plasmidial, que já foi citada como altamente discriminatória ${ }^{3,4}$, esbarra na ausência de material extra-cromossômico em algumas amostras, que passam a ser não tipáveis por este método ${ }^{2}$, e na facilidade com que podem ser transmitidos os plasmídeos, inclusive entre gêneros bacterianos diversos ${ }^{5}$. Sendo assim, tanto o antibiograma quanto o perfil plasmidial podem ser considerados métodos instáveis e de baixo poder discriminatório, salvo algumas exceções.

A sorotipagem e a fagotipagem dependem de reações de proteínas de membrana que devem estar expostas e serem reconhecidas por anticorpos ou bacteriófagos. Caso estas proteínas não estejam sendo expressas ou o painel de soros ou o de fagos não seja adequado para aquela linhagem, a reação não ocorre e a bactéria não pode ser tipada ${ }^{6,7}$. 
Por outro lado, o poder discriminatório das tipagens moleculares do cromossomo, assim como sua reprodutibilidade, é considerado tão elevado que lhe rendeu o nome de "impressão digital do DNA", do inglês, "DNA fingerprinting", 9 .

A tipagem molecular do cromossomo bacteriano envolve, na maioria das vezes, a análise do polimorfismo de fragmentos de restrição (RFLP do inglês, "restriction fragment length polymorfism") separados por algum tipo de eletroforese. A digestão do cromossomo bacteriano, por determinada enzima de restrição, resultará em um certo número de fragmentos, de tamanhos variados, mas que é constante para uma determinada linhagem ${ }^{8}$.

Caso uma mutação tenha ocorrido no sítio de reconhecimento de determinada enzima de restrição, a endonuclease não mais clivará o DNA cromossômico (crDNA) naquele ponto. O resultado será um fragmento a menos do que o esperado para aquele microorganismo, além do aumento de tamanho de um dos fragmentos. É, assim, pelo resultado de mutações acumuladas, que cada linhagem apresenta um padrão próprio de fragmentos de restrição. $\mathrm{O}$ tamanho desses fragmentos varia conforme a enzima empregada ou, mesmo, pode variar entre bactérias da mesma espécie quando se usa a mesma enzima. Isso é o que determina o polimorfismo entre bactérias da mesma espécie, sendo que polimorfismo é definido como sendo a ocorrência simultânea, numa dada espécie bacteriana, de genomas que apresentam variações, na sequiência de bases do seu DNA (Figura 1).

\section{2 - CONCEITO DE RIBOTIPAGEM}

O uso de endonucleases de restrição que reconhecem poucos sítios no cromossomo, resulta em fragmentos grandes que só podem ser separados por eletroforese de campo pulsante (PFGE do inglês, "pulsed field gel electrophoresis"). As enzimas que reconhecem seqüências mais comuns, ao clivarem o crDNA, produzem um número tão grande de fragmentos, e com tamanhos tão próximos, que dificultam sua separação. A hibridação com seqüências repetitivas marcadas (sondas moleculares) gera um padrão de bandas mais limitado e, portanto, de fácil interpretação ${ }^{10,11}$.

Em 1986, GRIMONT e GRIMONT ${ }^{12}$ desenvolveram a técnica de ribotipagem, utilizando o plasmídeo recombinante pKK3535 como sonda. A realização de hibridações com mais de 40 gêneros bacterianos comprovou seu valor taxonômico. O pKK3535 havia sido construído por BROSIUS et al., em $1981^{13}$, clonando os genes codificadores de RNA ribossômico (rRNA) de Escherichia coli (Figura 2).

Os três tipos de rRNA 23S, 16S e 5S, que fazem parte estrutural dos ribossomos, organizam-se em um opéron (opéron $r r n$ ), ou seja, dividem o mesmo sistema regulatório. O opéron $r r n$ é uma unidade policistrônica, que, ao ser transcrita, origina um único RNA precursor (30S), que, sofrendo o processo de maturação, resultará nos diferentes tipos de rRNA maduros ${ }^{14}$. A ocorrência de modificações pós-transcricionais em regiões altamente conservadas sugere a importância

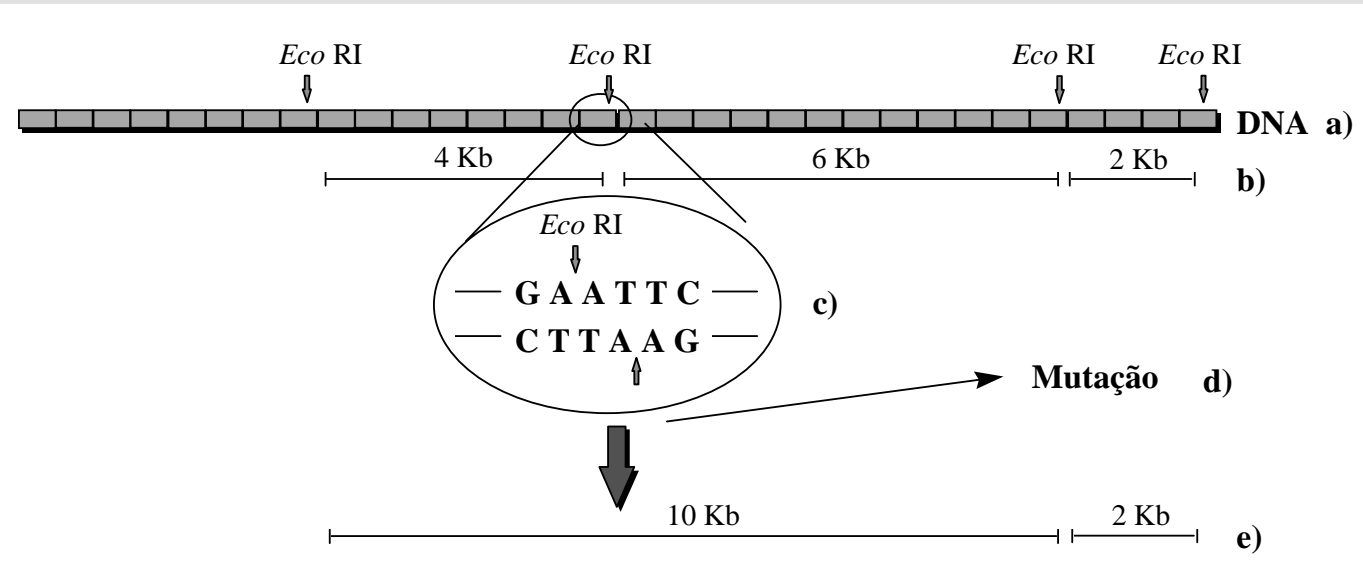

Figura 1 - Representação esquemática de polimorfismo do comprimento dos fragmentos de restrição (RFLP). a - seqüência de bases de DNA, indicando 4 sítios de restrição para a enzima Eco RI; $\boldsymbol{b}$ - número e tamanho (Kb) dos fragmentos de restrição obtidos após digestão com Eco Rl; $\boldsymbol{c}$ - detalhe, mostrando o sítio de restrição da Eco Rl; $\boldsymbol{d}$ - indicação de mutação na seqüência de bases que está em detalhe; $\boldsymbol{e}$ - número e tamanho $(\mathrm{Kb})$ dos fragmentos de restrição, obtidos pela digestão do crDNA com Eco Rl, após a mutação. 
destes genes. Seu papel fundamental na síntese protéica levou à seleção de microorganismos com mais do que uma cópia do opéron $r r n$ por cromossomo. Dependendo da espécie, o número de cópias varia de 2 a 11 por genoma haplóide. São raras as exceções de bactérias que apresentam apenas uma cópia de genes de rRNA no seu cromossomo, como, por exemplo, algumas linhagens de Mycobaterium spp e a Borrelia burgdorferi. Alguns pesquisadores citam que a ocorrência de um só opéron rrn estaria relacionada ao pequeno tamanho do genoma e à taxa lenta de crescimento bacteriano. B. burgdorferi exemplifica bem essa hipótese, uma vez que apresenta um genoma cinco vezes menor que o de E. coli, com apenas $10^{6}$ pares de base (pb), e é de crescimento lento ${ }^{15}$. O genoma de E. coli, por outro lado, apresenta sete opérons rrn, denominados de A a H, já bem caracterizados. Dados de seqüenciamento revelaram dois promotores, $\mathrm{P} 1 \mathrm{e}$ $\mathrm{P} 2$, indicados na Figura 2, espaçados cerca de $120 \mathrm{pb}$ entre si. Além disso, em cada opéron, os genes de rRNA $16 \mathrm{~S}$ e $23 \mathrm{~S}$ estão presentes em cópia única, mas o número de cópias do gene de rRNA 5S pode variar ${ }^{14}$. Ainda dentro destes opérons, encontram-se genes que codificam para RNA transportadores (tRNA), que podem se localizar entre os rRNA $16 \mathrm{~S}$ e $23 \mathrm{~S}$ ou, na parte mais distal do opéron, próximo ao gene $5 \mathrm{~S}^{16,17}$. Todas as fases abertas de leitura deste opéron apresentam regiões espaçadoras de função desconhecida.

Paradoxalmente, a conservação evolutiva dos genes de rRNA entre as eubactérias, assim como o polimorfismo observado dentro e fora destes opérons ${ }^{18}$, pelo acúmulo de mutações pontuais, inserções, transposições, duplicações, deleções e inversões, é que permite a discriminação entre linhagens. Assim, cada linhagem bacteriana apresenta um padrão próprio de fragmentos de restrição que, no caso da ribotipagem, é revelado pela hibridação com uma sonda contendo o opéron $r r n$.

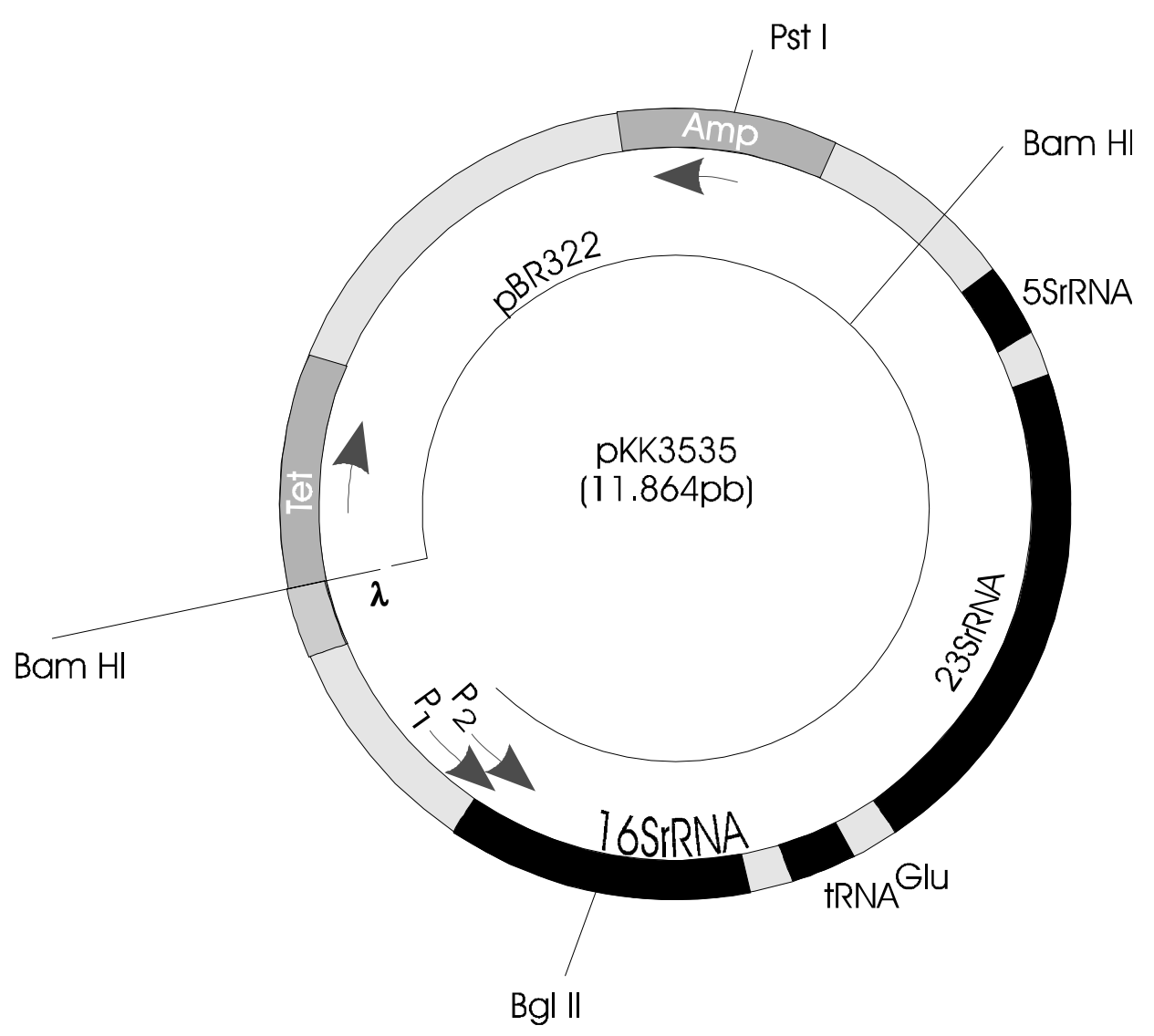

Figura 2 - Mapa esquemático do plasmídio híbrido pKK 3535. Posições do DNA vetor (pBR 322) ou insertos de outros plasmídeos, carregando partes do opéron rrnB estão indicados no círculo interno. A posição $\lambda$ e os genes de resistência à Ampicilina (Amp) e Tetraciclina (Tet) estão apresentados e a direção das transcrições estão indicadas por setas. Os genes para os rRNAs e o tRNA $A^{\text {Glu }}$ estão representados em barras pretas. Os promotores $P_{1}$ e $P_{2}$ e seus sítios de iniciação de transição estão indicados pelas setas. Sítios de restrição de enzimas Pst l, Bam HI e Bgl Il estão indicados na parte externa do plasmídeo. 


\section{3 - METODOLOGIA DA RIBOTIPAGEM}

A ribotipagem consiste na extração e purificação do DNA total da bactéria, digestão deste material com uma enzima de restrição, corrida eletroforética, transferência de fragmentos desnaturados para um filtro, hibridação com a sonda marcada e revelação do padrão de bandas.

Métodos, os mais variados, de extração e purificação de material nucléico têm sido descritos, na literatura, para a realização de ribotipagem. O uso de tiocianato de guanidina tem sido citado com maior freqüência por sua rapidez e praticidade ${ }^{19}$. Técnicas mais laboriosas que utilizam lisozima, proteinase K e SDS, seguidas de uma purificação com fenol e clorofórmio, entretanto, têm se mostrado mais eficientes, resultando em maior concentração de DNA por volume de amostra (dados próprios). No caso de Serratia marcescens, por exemplo, a etapa de purificação com fenol é imprescindível devido à presença de DNases inerentes ao gênero ${ }^{20}$.

A sensibilidade da ribotipagem em agrupar ou não espécies bacterianas, em linhagens específicas, está diretamente relacionada ao tipo de endonuclease de restrição empregada. A escolha da enzima apropriada deve basear-se em dados da literatura ou, quando estes forem escassos, inadequados ou inexistentes, no conteúdo de GC daquela espécie. Normalmente, testa-se mais que uma enzima para se determinar qual delas teria o melhor poder discriminatório para aquela espécie. GARAIZAR et al. ${ }^{6}$, por exemplo, compararam métodos convencionais com a ribotipagem para identificar 45 isolados de E. cloacae, de 36 pacientes de 9 hospitais. Foram utilizadas as enzimas Bam HI, Eco RI e Hind III, e, segundo os autores, as três se mostraram adequadas. Embora a conclusão do trabalho tenha indicado que tanto a ribotipagem quanto os quatro métodos fenotípicos, avaliados em conjunto, mostraram-se igualmente discriminatórios, chamou a atenção o fato de várias amostras não terem sido fenotipadas devido a reações inespecíficas com fagos ou soros. Nestes casos, a ribotipagem foi capaz de resolver os resultados inconclusivos, uma vez que qualquer amostra é passível de ser identificada pela análise de crDNA. A utilização de mais de uma enzima de restrição pode aumentar a capacidade da ribotipagem de identificar linhagens diferentes ${ }^{21}$.

A eletroforese se realiza em gel de agarose ( $0,8 \%$ em geral) em baixa voltagem, para que a separação dos fragmentos ocorra da melhor forma pos- sível. A separação efetiva de fragmentos de DNA linear maiores do que $2 \mathrm{~Kb}$ aumenta a baixas voltagens ${ }^{22}$. A desnaturação, na presença de excesso de sal e pH bastante alcalino, seguem o protocolo descrito por SOUTHERN ${ }^{23}$. Normalmente, se utiliza filtro de nylon, carregado positivamente, por ser mais resistente, permitindo que o mesmo filtro seja retestado com outras sondas, se for necessário. Outra vantagem do filtro de nylon sobre o de nitrocelulose é que, no primeiro, ocorre a ligação covalente de DNA através de irradiação, por três minutos, com luz ultra-violeta. No caso da nitrocelulose, é necessária uma hora a $80^{\circ} \mathrm{C}$, sob vácuo, para se fixar o material nucléico.

A marcação de sondas de ribotipagem pode ser feita com isótopos radioativos, ou, como tem sido descrito mais recentemente, por algum entre vários métodos frios ${ }^{24}$. O kit de marcação com digoxigenina (Boehringer-Mannheim) tem sido utilizado freqüentemente. A digoxigenina é um hapteno que, ligado ao dUTP, é incorporado à sonda, numa reação de duplicação catalizada por uma polimerase. Após a hibridação, o filtro é exposto a uma solução, contendo um anticorpo antidigoxigenina, ligado covalentemente a uma fosfatase alcalina. $\mathrm{O}$ anticorpo se ligará à digoxigenina, no local onde a sonda encontrou uma seqüência homóloga. A fosfatase alcalina cliva um substrato específico que é colocado em contato com o filtro e faz precipitar uma substância de cor azul-acinzentada, revelando o local onde ocorreu a hibridação.

A comparação dos padrões de bandas obtidos entre os diversos isolados pode ser feita visualmente ou por programas especializados de computador, como o MVSP ("Multi Statics Package", ${ }^{(25)}$ ), o PHYLIP ("Phylogeny Inference Package", ${ }^{(26)}$ ), o DENDRON ${ }^{(27)}$ ou o "DNA Fingerprinting"(28), por exemplo. Se duas amostras bacterianas apresentarem exatamente o mesmo padrão de bandas, trata-se de uma única linhagem bacteriana. Se o padrão for semelhante, mas não idêntico, deve-se fazer uma estimativa do grau de parentesco entre os clones. A avaliação da similaridade genética entre as amostras pode ser feita através de dendogramas ou pelo coeficiente de Dice (CD). O dendograma fornece valores em percentagens, onde a proximidade genética é estimada pela distância entre as amostras, percorrendo-se suas linhas verticais. Os programas de computador, acima citados, produzem este tipo de resultado. O coeficiente de Dice é mais utilizado quando a comparação é feita visualmente. Este coeficiente foi descrito por $\operatorname{DICE}^{29}$ e é obtido pela fórmula: 


$$
\mathrm{CD}=\frac{2 \mathrm{n}^{a=b}}{\mathrm{n}^{a}+\mathrm{n}^{b}}
$$

sendo:

$\mathrm{n}^{a=b}$, o número de fragmentos localizados na mesma posição, em ambas as amostras;

$n^{a}+n^{b}$, número total de fragmentos apresentados por ambas as amostras.

$\mathrm{O}$ valor encontrado do $\mathrm{CD}$ pode definir se as amostras são idênticas, similares ou diferentes, baseando-se nos critérios estabelecidos pelo laboratório de referência para tipagem de linhagens, da Universidade de Iowa, EUA ${ }^{(15)}$, resumidos na Tabela I.

Também, é imprescindível saber que pode ocorrer variação do número de bandas de uma mesma amos-

Tabela I - Avaliação da similaridade genética entre linhagens bacterianas utilizando o coeficiente da DICE (CD)

\begin{tabular}{lcl}
\hline Padrão & $C D$ & \multicolumn{1}{c}{ Observação } \\
\hline Idêntico & 1,00 & todas as bandas iguais \\
Similar & 0,90 a 0,99 & a maioria das bandas iguais \\
Diferente & $<0,90$ & raras bandas iguais \\
\hline
\end{tabular}

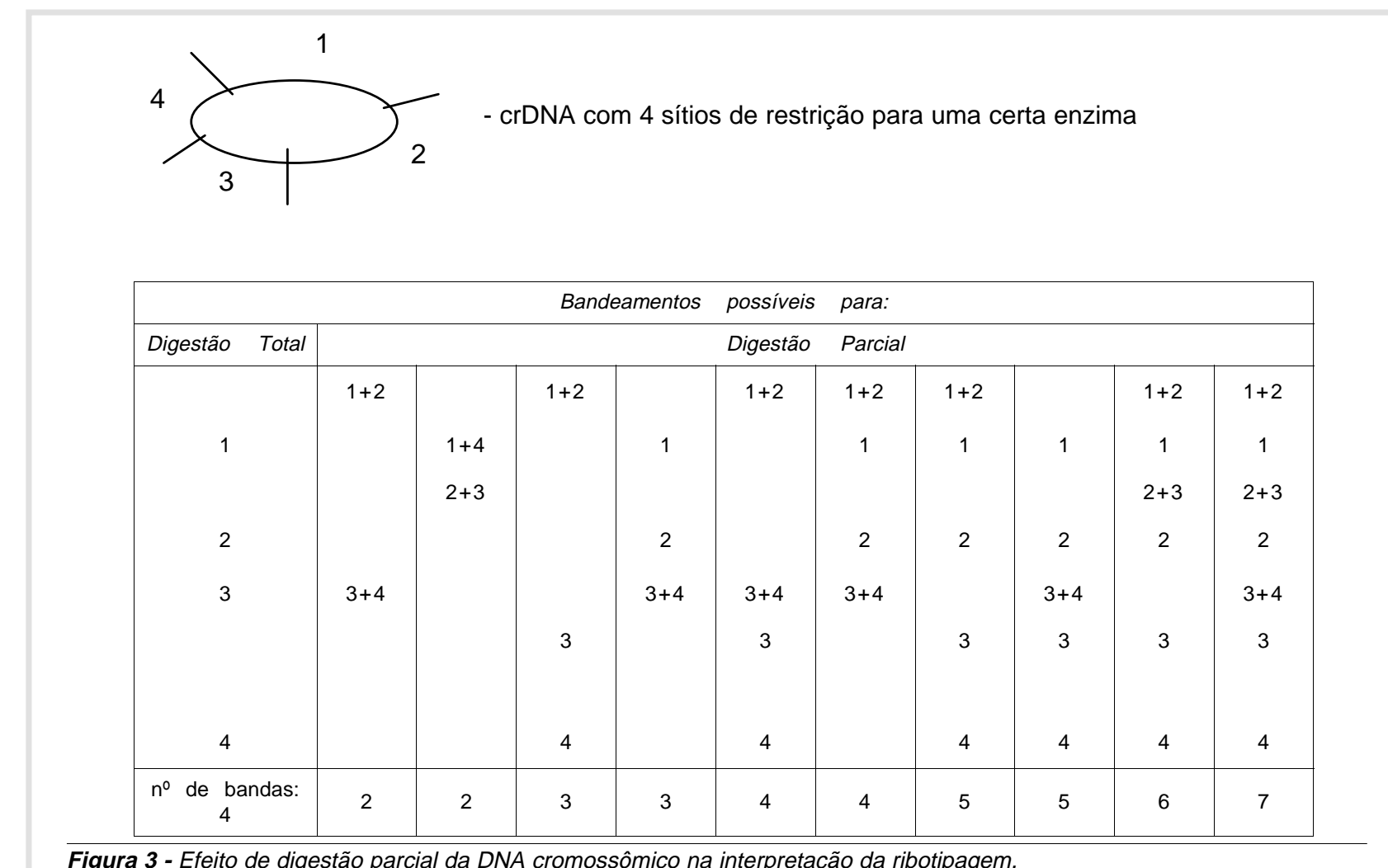

\begin{tabular}{|c|c|c|c|c|c|c|c|c|c|c|}
\hline \multicolumn{5}{|c|}{ Bandeamentos } & possiveis & \multicolumn{5}{|l|}{ para: } \\
\hline Digestão Total & & & & & Digestão & Parcia & & & & \\
\hline & $1+2$ & & $1+2$ & & $1+2$ & $1+2$ & $1+2$ & & $1+2$ & $1+2$ \\
\hline 1 & & $1+4$ & & 1 & & 1 & 1 & 1 & 1 & 1 \\
\hline & & $2+3$ & & & & & & & $2+3$ & $2+3$ \\
\hline 2 & & & & 2 & & 2 & 2 & 2 & 2 & 2 \\
\hline 3 & $3+4$ & & & $3+4$ & $3+4$ & $3+4$ & & $3+4$ & & $3+4$ \\
\hline & & & 3 & & 3 & & 3 & 3 & 3 & 3 \\
\hline 4 & & & 4 & & 4 & & 4 & 4 & 4 & 4 \\
\hline $\begin{array}{c}\text { no de bandas: } \\
4\end{array}$ & 2 & 2 & 3 & 3 & 4 & 4 & 5 & 5 & 6 & 7 \\
\hline
\end{tabular}

Figura 3 - Efeito de digestão parcial da DNA cromossômico na interpretação da ribotipagem. tra, ou entre amostras diferentes de uma mesma linhagem, usando a mesma enzima de restrição. Isso pode ser explicado por alguns problemas durante a execução da técnica, e exemplificados na Tabela II.

Entre esses motivos, o último deles (digestão normal de crDNA) é o mais comum, o que, na maioria das vezes, provoca erros na interpretação dos resultados. Havendo digestão parcial, pode-se obter tanto bandas a mais, quanto a menos, pois nem todos os DNA cromossômicos podem ter sido digeridos da mesma forma. O exemplo esquematizado na Figura 3 explica bem esse fato.

Tabela II - Possíveis problemas técnicos na execução de ribotipagem

- Observação prejudicada de uma ou mais bandas, pela escassez ou excesso de material.

- Migração acelerada de uma das amostras, permitindo melhor separação de bandas, conseqüentemente, também melhor observação.

- Problemas envolvendo a reação de hibridação, por exemplo, falta de homogeneidade da solução de hibridação sobre o filtro.

- Digestão parcial de crDNAs. 
No exemplo mostrado, ocorrendo digestão total, o esperado serão quatro bandas, ao passo que, se ocorrer falha técnica no preparo do experimento para uma ou mais amostras, poderá ocorrer digestão parcial, e o número de bandas pode ser de 2 a 7 para amostras idênticas.

O modo mais prático e confiável de se estabelecer se houve ou não digestão parcial de determinada amostra é por observação rigorosa do bandeamento de cada amostra, no gel de agarose. Bandeamento difuso, com acúmulo de material (crDNA clivado) no ponto de aplicação da amostra ou na extensão do bandeamento sugere digestão parcial.

\section{4 - APLICAÇÕES DA RIBOTIPAGEM}

Na Figura 4, encontra-se um exemplo da aplicação da ribotipagem. Pelo gel de agarose, após digestão do crDNA de E. cloacae com a enzima de restrição Sma I (Figura 4A), não é possível uma boa resolução visual das bandas, para comparação. Os fragmentos de DNA deste gel foram transferidos para um filtro de nylon e, após a hibridação com a sonda pKK3535 marcada com digoxigenina, o padrão de bandas permitiu uma análise inequívoca das amostras
(Figura 4B). A distância genética foi também avaliada pelo dendograma (Figura 4C). Somente os pares de amostras 1, 2 e 10, 11 apresentaram 100\% de similaridade, indicando tratar-se da mesma linhagem. Como as amostras foram obtidas de pacientes diversos, os dados sugeriram que houve infecção cruzada.

Sete amostras de E. cloacae, isoladas de diferentes pacientes internados em uma enfermaria ortopédica, em datas próximas, foram avaliadas quanto ao seu perfil de resistência a drogas, submetidas à fagotipagem e à ribotipagem após digestão do crDNA com SmaI. Três isolados não reagiram com nenhum dos fagos utilizados no painel, enquanto cinco amostras apresentaram resistência múltipla a drogas, o que não permitiu sua discriminação por este parâmetro. A ribotipagem revelou 5 linhagens diversas, sugerindo infecção cruzada apenas entre dois dos pacientes e descartando, assim, um surto na enfermaria ${ }^{30}$.

A ribotipagem não é, entretanto, a metodologia mais indicada para discriminação de linhagens de toda e qualquer eubactéria. Para bactérias Gram-positivas, por exemplo, utiliza-se um segundo plasmídeo como sonda, o $\mathrm{pSa}$, onde foi clonado o gene $16 \mathrm{~S}$ de Bacillus subtilis ${ }^{31}$, mas que apresenta um poder discriminatório menor que o da eletroforese de campo pulsante, considerada, hoje, o padrão ouro na tipagem

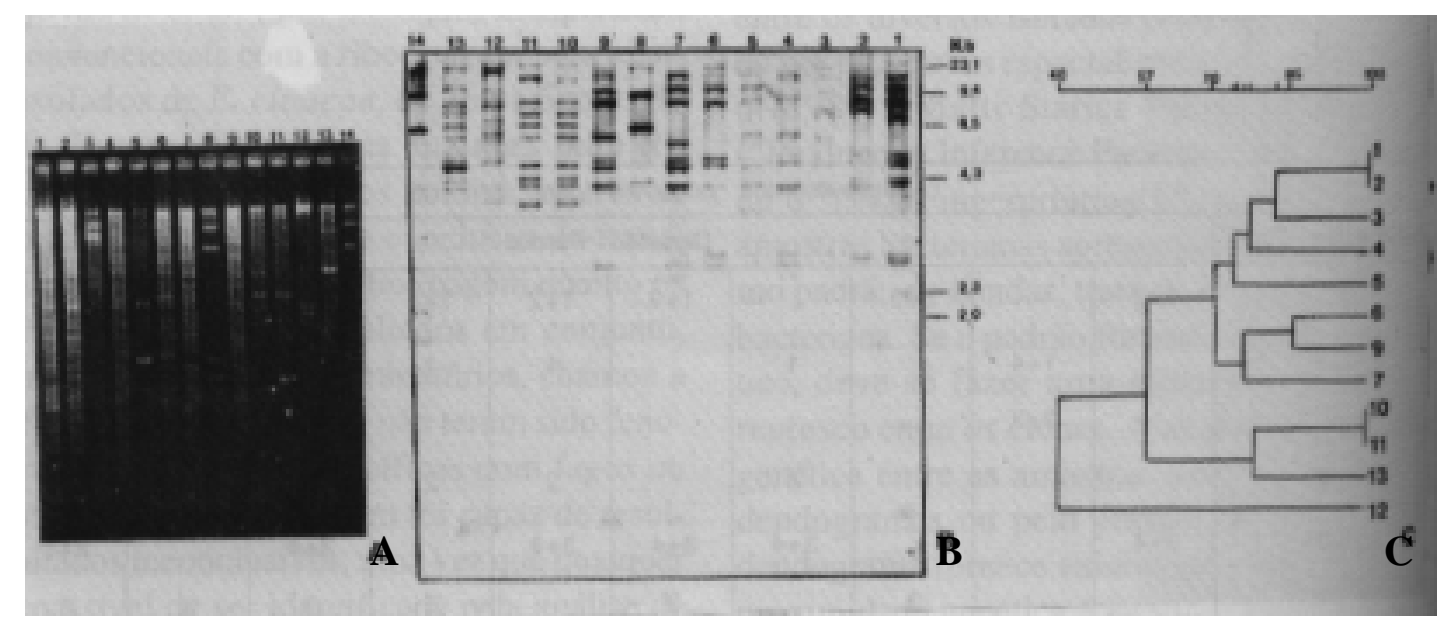

Figura 4 - Padrão de RFLP de crDNA, obtido pela digestão com Sma I. A - gel de agarose corado pelo brometo de etídio; linhas de 1 a 7 e de 9 a 13, amostras bacterianas Gram-negativas, isoladas de pacientes de uma enfermaria de um hospital universitário; linha 8, fago lâmbda digerido com Hind III como padrão de tamanho dos fragmentos de DNA; $\boldsymbol{B}$ - filtro de nitrocelulose, após transferência e detecção pelo método da digoxigenina; $\boldsymbol{C}$ - dendograma, representando a similaridade genética entre as amostras bacterianas. 
de Staphylococcus aureus ${ }^{32}$. Para M. tuberculosis, bactéria de crescimento lento e poucas cópias do opéron rrn, como já foi comentado, utiliza-se como sonda o transposon IS6110, que além de resultar em padrão polimórfico, devido a inserções em diferentes sítios no cromossomo bacteriano, tem papel diagnóstico, uma vez que é espécie-específico ${ }^{33}$.

Recentemente, a associação da reação em cadeia da polimerase (PCR) com a ribotipagem, o ribo-PCR, tem sido citada, na literatura, como uma estratégia vantajosa pois aliaria o poder discriminatório de uma abor- dagem à rapidez de outra ${ }^{34}$. Uma avaliação cuidadosa desta metodologia deve ser realizada com bactérias de diversos gêneros e epidemiologicamente bem definidas para se concluir por sua utilização de forma mais ampla.

Em conclusão, a ribotipagem, embora seja um método laborioso, tem sido comparada, favoravelmente, a métodos fenotípicos quanto ao seu poder discriminatório, podendo, também, vir a tornar-se uma abordagem de referência na identificação de linhagens de algumas espécies bacterianas.

DARINI ALC; MAGALHÃES VD \& CROTT LSP. Ribotyping on molecular epidemiology of bacterial infections. Medicina, Ribeirão Preto, 30: 73-80, jan./march. 1998.

ABSTRACT: Molecular typing usually involves restriction fragment analysis of chromossomal DNA. Since 1986, ribotyping has been used to analyse taxonomic and/or epidemiological relationship among microrganisms. Ribotyping uses, as an epidemiological tool, the restriction profile of the ribosomal RNA operons and it has provided good results in RFLP detection. The number of bacterial rrn operons correlates with the discriminatory potential of the technique.

UNITERMS: Epidemiology, Molecular. Bacterial Typing Techniques. Bacterial Infections.

\section{REFERÊNCIAS BIBLIOGRÁFICAS}

1 - DIJKSHOORN L et al. Correlation of typing methods for Acinetobacter isolates from hospital outbreaks. J Clin Microbiol 31: 702-705, 1993.

2 - GRATTARD F et al. Arbitrarily primed PCR, ribotyping, and plasmid pattern analysis applied to investigation of a nosocomial outbreak due to Enterobacter cloacae in neonatal intensive care unit. J Clin Microbiol 32: 596-602, 1994.

3 - TENOVER FC et al. Utility of plasmid fingerprinting for epidemiological studies of Campylobacter jejuni infections. J Infect Dis 149: 149-279, 1984.

4 - MAYER LW. Use of plasmids profiles in epidemiologic surveillance of disease outbreaks and in transmission of antibiotic resistence. Clin Microbiol Rev 1: 228-243, 1988.

5 - TORANZO AE et al. Plasmid coding for transferable drug resistance in bacteria isolated from cultured rainbow trout. Appl Environ Microbiol 48: 872-877, 1984.

6 - GARAIZAR J, KAUFMANN ME \& PITT TL. Comparison of ribotyping with conventional methods for type identification of Enterobacter cloacae. J Clin Microbiol 29: 1303-1307, 1991.

7 - HAERTL R \& BANDLOW G. Subtyping of Legionella pneumophila serogroup 1 isolates by small-fragment restriction endonuclease analysis. Eur $\mathbf{J}$ Clin Microbiol Infect Dis 10: 630-635, 1991.

8 - DARINI ALC. Métodos de tipagem epidemiológica de bactérias. Rev Bras Patol Clín 30: 14-19, 1994
9 - MAGALHÃES V \& COSCINA AL. O emprego da biologia molecular no controle de infecções hospitalares. Laes/Haes $\mathbf{9 2}$ 103-106, 1995.

10 - TENOVER FC. Diagnostic deoxyribonucleic acid probes for infectious diseases. Clin Microbiol Rev 1: 82-101, 1988.

11 - DARINI ALC. Sondas genéticas e sua aplicação em laboratório de microbiologia clínica. Laes/Haes 74: 8-19, 1992.

12 - GRIMONT F \& GRIMONT PAD. Ribossomal ribonucleic acid gene restriction patterns as potential taxonomic tools. Ann Inst Pasteur Microbiol 137B: 165-175, 1986.

13 - BROSIUS $\mathrm{J}$ et al. Construction and fine mapping of recombinant plasmids containing the $r r n$ B ribossomal RNA operon of E. coli. Plasmid 6: 112-118, 1981.

14 - NOLLER HF \& NOMURA M. Ribossomes. In: NEIDHARDT FC et al., eds. Escherichia coli and Salmonella typhimurium: cellular and molecular biology. American Society for Microbiology, Washington, p.104-125, 1987.

15 - BINGEN EN, DENAMUR E \& ELION J. Use of ribotyping in epidemiological surveillance of nosocomial outbreaks. Clin Microbiol Rev 7: 311-327, 1994.

16 - SRIVASTAVA AK \& SCHLESSINGER D. rRNA processing in E. coli. In: HILL WE et al.,eds. The ribossome: structure, function \& evolution. American Society for Microbiology, Washington, p.426-434, 1990.

17 - BACOT CM \& REEVES RH. Novel tRNA gene organization in the 16S-23S intergenic spacer of the Streptococcus pneumoniae rRNA gene cluster. J Bacteriol 173: 4234-4236, 1991. 
18 - TENOVER FC. Molecular biology. In: ISENBERG HD. Clinical microbiology procedures handbook. American Society for Microbiology, Washington, p.10.0.1-10.6.3, 1992.

19 - PITCHER DG; SAUNDERS NA \& OWE RJ. Rapid extraction of bacterial genomic DNA with guanidium thiocyanate. Lett Appl Microbiol 8: 151-156, 1989.

20 - ALONSO R; NICHOLSON PS \& PITT TL. Rapid extraction of highly purity chromosomal DNA from Serratia marcescens. Lett Appl Microbiol 16: 77-79, 1993.

21 -GERNER-SMIDT P. Ribotyping of the Acinetobacter calcoaceticus-Acinetobacter baumanii Complex. J Clin Microbiol 30: 2680-2685, 1992.

22 - SAMBROOK J; FRITSCH EF \& MANIATIS T. Molecular cloning: a laboratory manual. Cold Spring Harbor Laboratory Press, New York, p. 6.3-6.6, 1989.

23 - SOUTHERN EM. Detection of specific sequences among DNA fragments separated by gel electrophoresis. J Mol Biol 98: 503-517, 1975.

24 - GUSTAFERRO CA \& PERSING DH. Chemiluminescent universal probe for bacterial ribotyping. J Clin Microbiol 30: 1039-1041, 1992.

25 - KOVACK WL. Kovack computing service. Anglesey, Wales, 1993 /disquete/

26 - FELSENSTEIN J. Using Phylip: the short form of the instructions. Seattle. Washington. U.S.A. 1991 /disquete/

27 - SCHIMID J VOSS E \& SOLL DR. Computer-assisted methods for assessing strain relatedness in Candida albicans fingerprinting with the moderately repetitive sequence Ca3. J Clin Microbiol 28: 1236-1243, 1990.
28 - SAITOU \& NEI. NJ Algorithm. Mol Biol Evol 4: 406-425, 1987.

29 - DICE LR. Measures of the amount of ecological association between species. Ecology 26: 379-393, 1945.

30 - MAGALHÃES VD et al. Comparação de antibiograma, fagotipagem e ribotipagem na discriminação de linhagens hospitalares de Enterobacter cloacae. Newslab 6: 26-28, 1994.

31 - SOLH NE et al. Use of Bacillus subtilis $16 \mathrm{~S}$ rRNA genes as a probe to identify species, subspecies, and types in the genus Staphylococcus. In: NOVICK RP. Molecular biology of the Staphylococci. VCH Publishers, New York, p.585-593, 1990.

32 - PREVOST G; JAULHAC B \& PIEMONT Y. DNA fingerprinting by pulsed field gel electrophoresis is more discriminant than ribotyping in distinguishing among methicillin resistant Staphylococcus aureus isolates. J Clin Microbiol 30: 967-973, 1992.

33 - NEIMARK H; BAIG MA \& CARLETON S. Direct identification and typing ;f Mycobacterium tuberculosis by PCR. J Clin Microbiol 34: 2454-2459, 1996.

34 - KOSTMAN JR et al. Molecular epidemiology of Pseudomonas linhagemcia determined by polymerase chain reaction ribotyping. J Clin Microbiol 30: 2084-2087, 1992.

Recebido para publicação em 21/05/97.

Aprovado para publicação em 29/10/97. 